\title{
Uma nova espécie de Euplusia da Bahia, Brasil (Hymenoptera, Apoidea, Euglossinae) ${ }^{1}$
}

\author{
Jesus Santiago Moure ${ }^{2}$ \\ Edinaldo Luz das Neves ${ }^{3,4}$ \\ Blandina Felipe Viana ${ }^{3}$
}

\begin{abstract}
A new species of Euplusia from Bahia, Brazil (Hymenoptera, Apoidea, Euglossinae). Euplusia aridicola sp. n., a member of the short tongued group, is described as a new species. It can be easily recognized by the large white yellowish pubescence on the sides of terga second to fourth, the bright anterior half of mesoscutum covered by yellowish hairs; clypeus medially bicarinate. The holotype was colleted in Ibiraba, Barra, a semi-arid region of Bahia, Brazil, using eucalyptol, as an attractant.

KEY WORDS. Hymenoptera, Apoidea, Euglossinae, Euplusia, Neotropical
\end{abstract}

Para fazer um levantamento dos Apoidea do Estado da Bahia, estão sendo reunidas informações, literatura e exemplares que permitam uma melhor visão de conjunto da fauna e flora do Estado num trabalho que envolve vários departamentos da Universidade Federal da Bahia, em colaboração com a Universidade Estadual de Freira de Santana, e, para estudo de Hymenoptera, a Universidade Federal do Paraná.

Aqui dá-se a conhecer uma espécie nova de Euglossinae. Trata-se de um representante destas abelhas que desempenham papel importante como polinizadoras de vários grupos de plantas, os machos como visitantes de flores de orquídeas e as fêmeas, de várias familias diferentes de plantas.

Os machos, pela sua maior possibilidade de captura com o uso de essências artificiais, facilmente adquiridas no comércio, tem significativamente aumentado nossa coleção, e, pelo número de indivíduos capturados em toda a região Neotropical, tem chamado mais a atenção dos pesquisadores particularmente KIMSEY \& DRESLER (1986) que publicaram uma lista das espécies deste gênero, facilitando o trabalho de pesquisadores subseqüentes, principalmente quando escasseiam os trabalhos originais.

Em levantamento realizado nas matas ciliares de Ibiraba $\left(10^{\circ} 148 \mathrm{~S}, 42^{\circ} 15^{\prime}\right)$ situada na margem esquerda do médio Rio São Francisco, município de Barra, que está numa região semi-árida do Estado da Bahia, E.L. Neves \& B.F. Viana

1) Contribuição número 1236 do Departamento de Zoologia, Universidade Federal do Paraná.

2) Departamento de Zoologia, Universidade Federal do Paraná. Caixa Postal 19020, 81531-990 Curitiba, Paraná, Brasil. Bolsista do CNPq. E-mail: urban@bio.ufpr.br

3) Departamento de Zoologia, Instituto de Biologia, Universidade Federal da Bahia. Rua Barão de Geremoabo, Campus de Ondina, 40170-110 Salvador, Bahia, Brasil.

4) Bolsista PEP/UFBA e PIBIC/CNPq/UFBA. 
capturaram um exemplar desta nova espécie de Euglossinae do gênero Euplusia Moure, 1943 pertencente ao grupo auriceps. A abelha foi atraída por uma isca com eucaliptol. Entre as abreviações usadas destacamos dp, diâmetro de ponto, para indicar o distanciamento entre os mesmos de um modo mais objetivo; medidas entre parêntesis em centésimos de milímetros.

\section{Euplusia aridicola sp. $\mathbf{n}$.}

Figs 1-4

Macho. Comprimento total aproximado $15,7 \mathrm{~mm}$; da asa anterior desde o esclerito costal 15,8 mm; largura da cabeça $6,40 \mathrm{~mm}$; do segundo tergo $7,50 \mathrm{~mm}$; comprimento da porção pós-palpal da gálea $6,83 \mathrm{~mm}$, alcançando as coxas posteriores.

Cabeça de cor verde-metálica brilhante passando a purpúrea na parte média incluindo as carenas e a depressão clipeal entre as mesmas, as áreas paroculares superiores de um verde mais brilhante; genas verde-garrafa-escuro, quase preto; no vértice com reflexos violáceos. Tórax com a metade anterior, na área correspondente às manchas escutais do mesonoto, de cor esverdeada; o restante do mesonoto, escutelo e lados do tórax de um negro violáceo revestido de pilosidade de igual cor, passando a um pouco esverdeado abaixo da região escrobal. Tégulas de cor esverdeada na metade anterior e azul-violácea na posterior; asas escurecidas, mais acentuadamente as células marginal e radial, com o estigma e venação pretos; pernas anteriores e médias com alguns reflexos entre azul e violáceo; as posteriores praticamente pretas. Propódeo em parte esverdeado-violáceo; T1 largamente violáceo, para o ápice mais desbotado; desta mesma cor T2-4 com reflexos de colorido verde-brônzeo, mais acentuado em T2; T5-7 de um verde-garrafa mais evidente.

Pilosidade, na metade inferior da face e na fronte, esbranquiçada; no vértice e nas genas, parcialmente ocrácea e negra; em frente aos ocelos laterais ocráceoamarelada; com alguns pêlos muito curtos na fronte e faltando quase completamente até o meio da face externa, na metade frontal ao sulco médio. Negra no pronoto e na extremidade anterior do mesoscuto; sobre a área verde anterior das manchas escutais com pilosidade clara, ligeiramente palha; na metade posterior do mesoscuto, no escutelo e lados do tórax, preta. Nas pernas preta, porém na face externa dos basitarsos médios, branca; a franja ciliar ântero-distal das tíbias médias bem desenvolvida, com grossas cerdas pretas, afastada da área aveludada de cor castanho-escura em certa luz. Alguns pêlos pálidos no lado externo superior das tíbias posteriores. No abdome preta com uma faixa amarelo-palha no T2 chegando aos lados até o bordo anterior e profundamente recortada em semicírculo na parte média quase desligando os dois lados, deixando uma área preto-pilosa, recurva, quase atingindo o bordo apical; em T3 com pilosidade palha nos quartos laterais, sem se prolongar para o meio; em T4 os pêlos amarelo-palha cobrindo apenas as extremidades laterais, em T5 toda superfície sem formar manchas limitadas aos extremos laterais; T6 um pouco menos piloso com alguns pêlos pretos no disco; em T7 a pilosidade palha esparsa, mais longa e, em geral, ereta. 


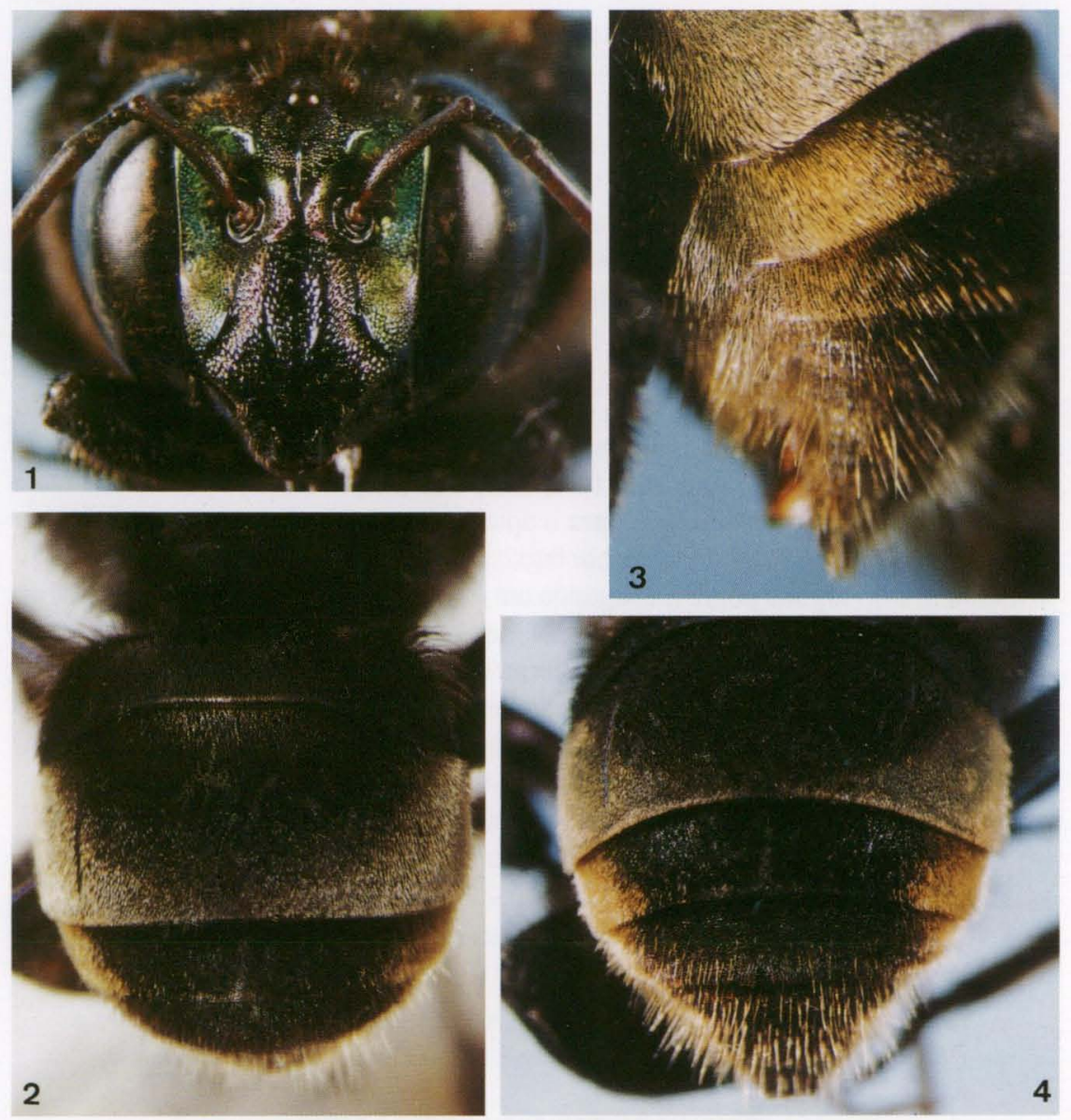

Figs 1-4. Euplusia aridicola sp. n., holótipo. (1) cabeça em vista frontal; (2-4) abdome.

Pontuação densa na face, relativamente grossa com pontos de $60-70 \mu$, quase nula na linha média reticulada da depressão clipeal e nas carenas laterais e linha média aos lados do sulco interalveolar. As carenas látero-ocelares em forma de cálice ligadas às supra-alveolares com pontuação densa mais grossa para baixo; as supra-alveolares em parte lisas e brilhantes, entre as látero-ocelares com pontuação densa de vários tamanhos, mais fina contornando a estreita área lisa em frente ao ocelo médio, aos lados dos ocelos posteriores ligeiramente mais lisa em direção às órbitas; nas genas mais fina e mais densa em cima e mais grossa e esparsa embaixo. No mesoscuto densa anteriormente, muito mais esparsa e claramente de dois tamanhos no disco da metade posterior do mesoscuto e no escutelo também de dois tamanhos porém um pouco mais densa; no disco posterior do mesoscuto os pontos mais grossos e esparsos com intervalos entre 4-6 dp e os pontos muito mais finos intercalados com intervalos lisos de cerca de $2 \mathrm{dp}$; no escutelo os pontos menores 
mais freqüentes com os intervalos lisos de 1-1,5 dp. Densa nos meso- e metaepisternos. $\mathrm{Na}$ área basal do propódeo fina e grossa misturadas, os pontos grossos relativamente mais esparsos, com a depressão média basal bastante marcada; para os flancos muito mais esparsa e mais fina, rodeada de pontos grossos e mais densos junto à sutura anterior; nos tergos densa e fina, muito uniforme. As tíbias posteriores na face externa com pontuação densa para a base e para o bordo anterior, muito mais esparsa em frente à fenda tibial, os intervalos micro-rugulosos superficialmente.

Cabeça mais larga que longa (608:515); olho (458:233); área malar linear; distância clipeo-ocelar 0,83 vezes o comprimento do clípeo (170:205); gálea 1,47 vezes o comprimento do olho. No clípeo com duas carenas relativamente fortes ligadas superiormente em ferradura estreita desde a base porém encurtada antes do bordo apical, deixando uma linha média micro-rugulosa superficialmente bastante lisa entre as carenas. O labro com forte carena média, na base as carenas laterais fracamente curvas, convergentes para o ápice e formando distalmente um ângulo quase reto de vértice arredondado e por baixo destes uma área lisa um pouco inchada, brilhante e com alguns pontos, chegando até o bordo do labro. A área aveludada da face externa das tíbias médias com a curvatura posterior regular, inferiormente não atingindo o ápice da tíbia, com o tufo anterior em triângulo muito estreito sem atingir a franja distal bem formada por cerdas grossas pouco recurvas. Tíbias posteriores com franja posterior à fenda glandular formada de cerdas longas e esparsas, amarelentas, com algumas cerdas pretas misturadas.

Holótipo macho. BRASIL, Bahia: Barra (povoado de Ibiraba), 10-III-1997, E.L. Neves \& B.F. Viana leg., depositado na Coleção de Entomologia Pe. Jesus S. Moure, Departamento de Zoologia, Universidade Federal do Paraná (DZUP).

Etimologia. $\mathrm{O}$ nome específico lembra a área habitada pela espécie.

AGRADECIMENTOS. Ao PEP/UFBA e PIBIC/CNPq/UFBA pelas bolsas concedidas. Ao Prof. Dr. Albino Morimasa Sakakibara pelas fotos do tipo e leitura crítica do trabalho.

\section{REFERÊNCIA BIBLIOGRÁFICA}

Kimsey, L.S. \& R.L. DRESSLER. 1986. Synonymic species list of Euglossini. Pan-Pacific Entomologist 62 (3): $229-236$.

Recebido em 18.V.2000; aceito em 16.VIII.2001 